\title{
Hegazkinen elektrifikazioa: aktuatzaile elektromekanikoak eta propultsio elektrikoa
}

\author{
Aircraft electrification: electromechanical actuators \\ and electric propulsion
}

Andres Mauricio Sierra*1, Edorta Ibarra ${ }^{2}$, Inigo Kortabarria $^{2}$, Jon Andreu $^{2}$,
Joseba Lasa $^{1}$

LABURPENA: Gaur egun, elektrifikazio-maila altuak dituzten hegazkinak (MEA, More Electric Aircraft, ingelesez) kontuan hartzen dira aireko garraio ekologikoagoa, jasangarriagoa eta eraginkorragoa lortzeko. Alde horretatik, tradizionalak diren sistema pneumatikoak, hidraulikoak, eta mekanikoak sistema elektrikoengatik ordezkatu nahi dira, denborarekin, MEA kontzeptuaren helburuak lortzeko. Bi aplikazio elektriko nabarmentzen dira MEA motako hegazkinetan: aktuadore elektromekanikoak (EMA, Electro Mechanical Actuator, ingelesez) eta propultsio elektrikoa/hibridoa. Teknologia horien teknologiaren egoera garatzen da lan honetan, eta egileek EMA prototipo erreal batean lortutako emaitzak azaltzen dira. Horrez gain, sistema horien elementu nagusi diren potentzia-sistemak eta motor elektrikoak aztertzen dira, industria aeronautikoaren beharrizan zorrotzak direla-eta egokienak izan daitezkeen fase anitzeko topologietan zentratuz.

HITZ GAKOAK: MEA, aktuadore elektromekanikoak, propultsio elektrikoa, fase anitzeko motor elektrikoak.

ABSTRACT: Nowadays, More Electric Aircrafts (MEA) are gaining attraction in order to achieve a more ecological, sustainable and efficient air transportation. In this context, traditional pneumatic, hydraulic and mechanical systems are being progressively substituted by electric systems. Two applications can be high-lighted in MEAs: Electro Mechanical Actuators (EMA) and electric/hybrid propulsion. In this work, the state of the art of both applications is presented, showing experimental results obtained by the authors in a real EMA prototype. Additionally, the power electronics and electric machines that constitute such systems are studied, focusing on multiphase topologies that could meet the strict requirements of the aeronautical industry.

KEYWORDS: MEA, electromechanical actuators, electric propulsion, multiphase machines.

\footnotetext{
* Harremanetan jartzeko / Corresponding author: Andres Mauricio Sierra. Industria eta Garraio Saila, TECNALIA, Donostiako Parke Teknologikoa, Mikeletegi Pasealekua, 7, E-20009 Donostia-San Sebastián, Gipuzkoa, Euskal Herria. - andres.sierra@ tecnalia.com - https://orcid.org/0000-0002-7091-7485.

Nola aipatu / How to cite: Sierra, Andres Mauricio; Ibarra, Edorta; Kortabarria, Iñigo; Andreu, Jon; Lasa, Joseba (2019). «Hegazkinen elektrifikazioa: aktuatzaile elektromekanikoak eta propultsio elektrikoaw; Ekaia, 35, 2019, 257-275. (https://doi. org/10.1387/ekaia.19780).

Jasoa: 24 maiatza, 2018; Onartua: 20 uztaila, 2018.

ISSN 0214-9001 - eISSN 2444-3255 / (c) 2019 UPV/EHU
}

cc)(i) () Obra hau Creative Commons Atribución 4.0 Internacional-en lizentziapean dago 


\section{SARRERA}

Gaur egun, beharrezkoa da eraginkorrak diren eta ingurugiroa errespetatzen duten garraio-sistemen ikerketa eta garapena. Aireko garraioari dagokionez, elektrifikazio-maila altuak dituzten hegazkinak (MEA, More Electric Aircraft, ingelesez) hartzen dira jarraitu beharreko paradigmatzat [1]. MEAren helburua da hegazkin eraginkorrak eta ekologikoak garatzea, sektore aeronautikoan propioak diren fidagarritasun, segurtasun eta eskuragarritasun handiak mantenduz [2,3]. Helburu horiek guztiak lortzeko, hegazkinetan sistema elektrikoek duten presentzia handitzea bilatzen da MEA kontzeptuaren bidez.

Konbentzionalki, lau sistema mota nagusi erabiltzen dira hegazkinetan: sistema pneumatikoak, hidraulikoak, mekanikoak eta elektrikoak [1, 3, 4]. Motorrek sortutako airea aprobetxatzen dute sistema pneumatikoek, hegazkinaren ingurugiroaren kontrola (presurizazioa eta aire girotua) eta hegaletako izotzaren aurkako sistemak gauzatuz. Aldiz, hegazkinaren eragintza guztiaz arduratzen dira sistema hidraulikoak: lurreratze-trena, balaztak eta hegaldirako kontrol-aktuadoreak, besteak beste. Bestalde, erregaiaren eta olioaren ponpaketaz arduratzen da sistema mekanikoa. Azkenik, argiztapen-sistemaz, entretenimendu-sistemaz eta hegazkinaren elektronikaz arduratzen dira sistema elektrikoak. Alde horretatik, sistema horiek guztiek hegazkinaren konbustiozko motorretatik edota turbinetatik jasotzen dute energia, 1. irudiak erakusten duen bezala.
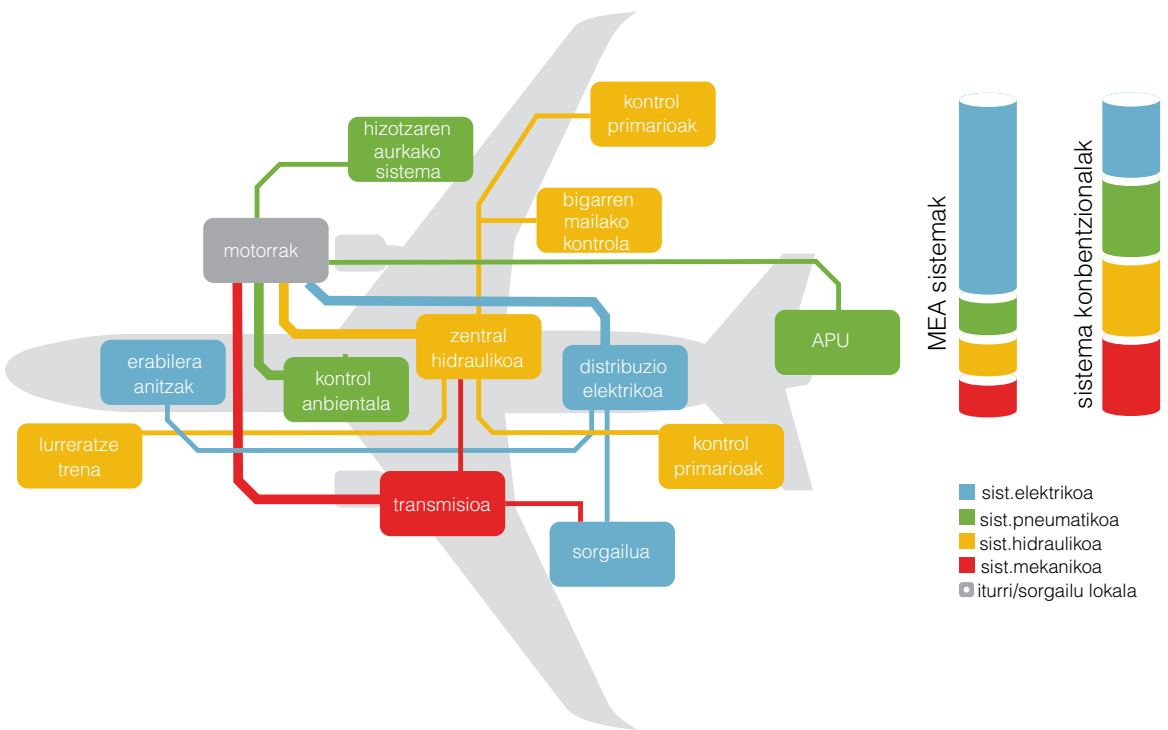

- sist.elektrikoa

sist.pneumatikoa

sist.hidraulikoa

sist.mekanikoa

- iturri/sorgailu lokala

1. irudia. Hegazkin konbentzional baten energia-iturriak eta sistemak. 
Aldiz, MEA kontzeptuak (2. irudia) sistema elektrikoek hegazkinetan duten protagonismoa handitzea proposatzen du. Hau da, propultsio-motorretik lau sistema mota izan beharrean, MEAk proposatzen duena da iturri horretatik sorkuntza-elektrikoa bakarrik elikatzea (2. irudia). Horrela, sorgailu elektrikoak elikatuko ditu azpisistema guztiak. Era horretara, konpresore elektrikoek ordezkatuko dituzte sistema pneumatikoak, erregaiaren ponpaketa ponpa elektrikoen bidez gauzatuko da eta eragintza hidrauliko guztia aktuadore elektromekanikoek ordezkatuko dituzte. Horren guztiaren helburua da sistema konbentzionalek dituzten desabantailak neurri batean saihestea. Adibidez, eragintza hidraulikoari dagokionez, olio-banaketarako sistema bat behar da, handia eta pisutsua dena, eta sarritan isurketak sortzen dituena [1,3]. MEA kontzeptuaren beste abantaila bat da sistema konbentzional bakoitza konektatuta duen kargaren potentzia maximoari erantzuteko diseinatuta dagoela. Hala ere, potentzia-mutur horiek ez dira aldi berean ematen; energia-iturriak sistema elektrikoan bateratuz, osagaien dimentsionamendu egokiagoa egin daiteke, hegazkinaren beharrizan errealetara hobeto egokituz. Ondorioz, hegazkinaren pisua eta bolumena nabarmen murriztu daiteke.

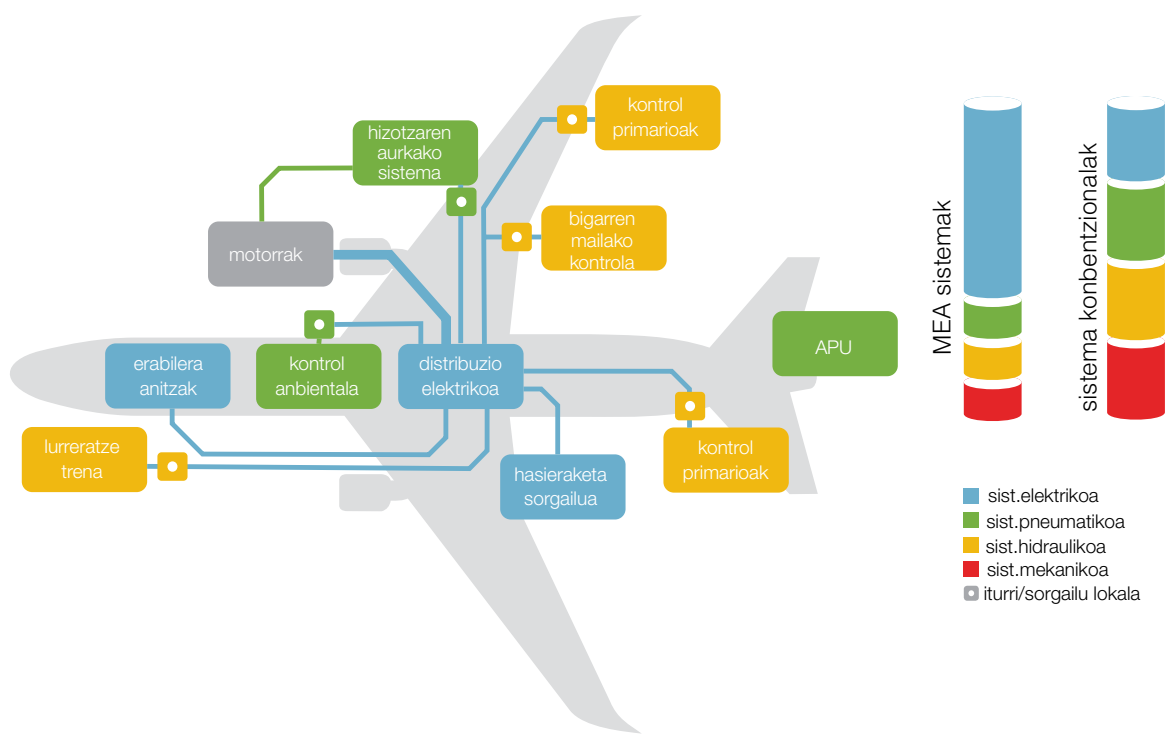

2. irudia. MEA hegazkin bateko potentzia-iturriak eta sistemak.

Bestalde, sistema elektrikoek dituzten abantailak aprobetxatu nahi dira MEA arkitektura daukaten hegazkinetan. Abantaila horien adibide dira eraginkortasun altua, pisu eta bolumen baxua (erregaia aurreztuz), segurtasuna, fidagarritasuna eta eskuragarritasuna. Energia elektrikoa bakarrik 
sortzen denez, sistema sinplifikatu egiten da, eta akatsak gertatzeko aukerak asko murrizten dira, hala nola akats mekanikoak, suteak eta leherketak gertatzeko aukerak.

MEA kontzeptuari esker lortuko diren abantaila horiek guztiak potentzia-elektronikan, energia elektrikoaren metaketan eta banaketan, makina elektrikoetan eta informazioaren eta komunikazioaren teknologietan egindako aurrerapenei esker gauzatu daitezke. Potentzia-elektronikari dagokionez, teknologia horren teknologiaren egoerak eraginkortasun handiko, bolumen eta pisu baxuko eta malgutasun handiko teknologiak ahalbideratzen ditu. Horrez gain, banaketa elektrikorako sistema malguagoak ahalbideratzen ditu, potentziazko kableatuaren pisua eta bolumena txikituz eta energia berriztagarrietan oinarritutako sorkuntza-sistemen integrazioa posible eginez. Informazioaren eta komunikazioaren teknologiek, aldiz, informazioaren eta kontrol-sistemen deszentralizazioa ahalbideratzen dute, komunikaziorako beharrezkoa den kable kopurua murriztuz. Konputazio-gaitasuna gero eta handiagoa denez, posible da gero eta konplexuagoak diren sistemak modu eraginkorrean kontrolatzea. Azkenik, motor eta sorgailu elektrikoei dagokienez, gaur egungo teknologiak potentzia-dentsitate eta eraginkortasun altuak eskaintzen dituzte, eta hutsegite-tolerantzia egokia ere eskaintzen dute.

Aipatutako ezaugarriak betetzen dituzten motor elektrikoak eta potentzia-sistemak beharrezkoak dira MEA arkitektura batean, honako bi aplikazio hauek posible egiteko:

- Aktuazio elektromekanikoa. Gaur egun hegazkinek darabiltzaten sistema hidraulikoen ezaugarriak hobetzea ahalbideratuko duen teknologia.

- Propultsio elektrikoa. Helburua du hegazkinetan erregai fosilen kontsumoa murriztea. Bestalde, posible izango da hegazkinek sortzen duten zarata murriztea ere.

Artikulu honetan, teknologia horien artearen egoeraren azterketa egiten da, eta horiek ahalbideratuko dituzten teknologiak (motor elektrikoak eta potentzia sistemak) aztertuko dira, industria aeronautikoaren beharrizan zorrotzak direla-eta egokienak izan daitezkeen fase anitzeko topologietan zentratuz.

\section{AKTUADORE ELEKTROMEKANIKOAK MEA SISTEMETAN}

Aeronautikaren esparruan, hegazkina lurrean edota airean maniobratzea ahalbidetzen duten sistemei deritze aktuadore [4]. Tradizionalki, bi multzotan banatzen dira aktuadoreak, horiek hegazkinean duten garrantziaren eta kritikotasunaren arabera $[4,5,6]$ : 


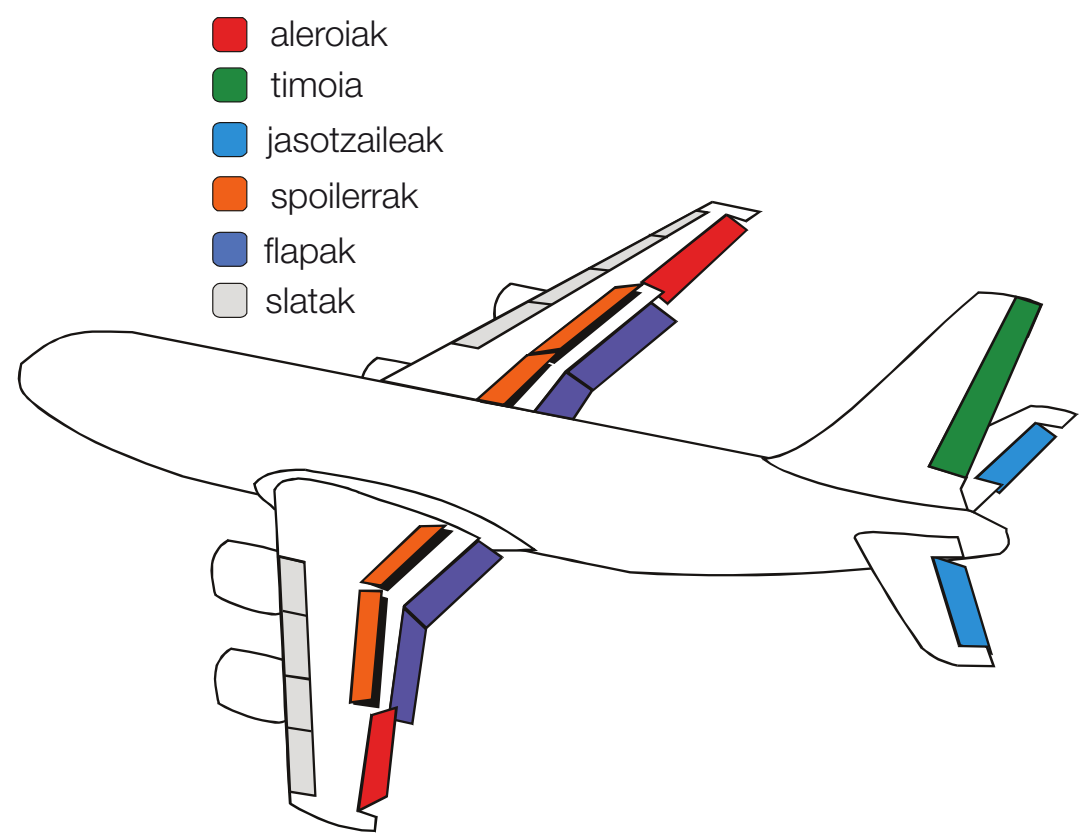

3. irudia. Hegaldiaren kontrolerako azalera esanguratsuenak.

- Hegaldirako kontrol primariorako aktuadoreak (3. irudia). Mota horretako aktuadore nagusiak dira aleroiak, timoia (rudder ingelesez) eta jasotzaileak (elevators, ingelesez). Ardatz longitudinalaren inguruko errotazioa (roll ingelesez) kontrolatzen dute aleroiek. Aldiz, ardatz bertikalaren inguruko errotazioa (yaw ingelesez) kontrolatzen du timoiak. Azkenik, zeharkako ardatzen inguruko errotazioa (pitch ingelesez) kontrolatzen dute jasotzaileek.

- Aktuadore sekundarioak (3. irudia). Talde honetan spoilerrak, flapak, slatak, lurreratze-trena, eta abar kontsideratzen dira. Hegazkinak airearekiko duen erresistentzia gehitu daiteke spoilerren bidez; horrela, posible da hegazkinak altuera jaistea aurreko muturra jaitsi gabe eta abiadura handitu gabe. Bestalde, lurreratzean eta aireratzean sostengu-koefizientea handitzeko erabiltzen dira flapak. Flapen antzeko funtzioa betetzen dute slatek, hau da, aldiune labur batean zehar aldatzen dute hegalen forma sostengua handitzeko.

Sistema horien adibide modura, egileek garatutako lurreratze-trenerako EMA erakusten du 4. irudiak [7], ATR hegazkin komertzial batean instalatuta dagoena, frogak gauzatzeko. 
Andres Mauricio Sierra, Edorta Ibarra, Iñigo Kortabarria, Jon Andreu, Joseba Lasa

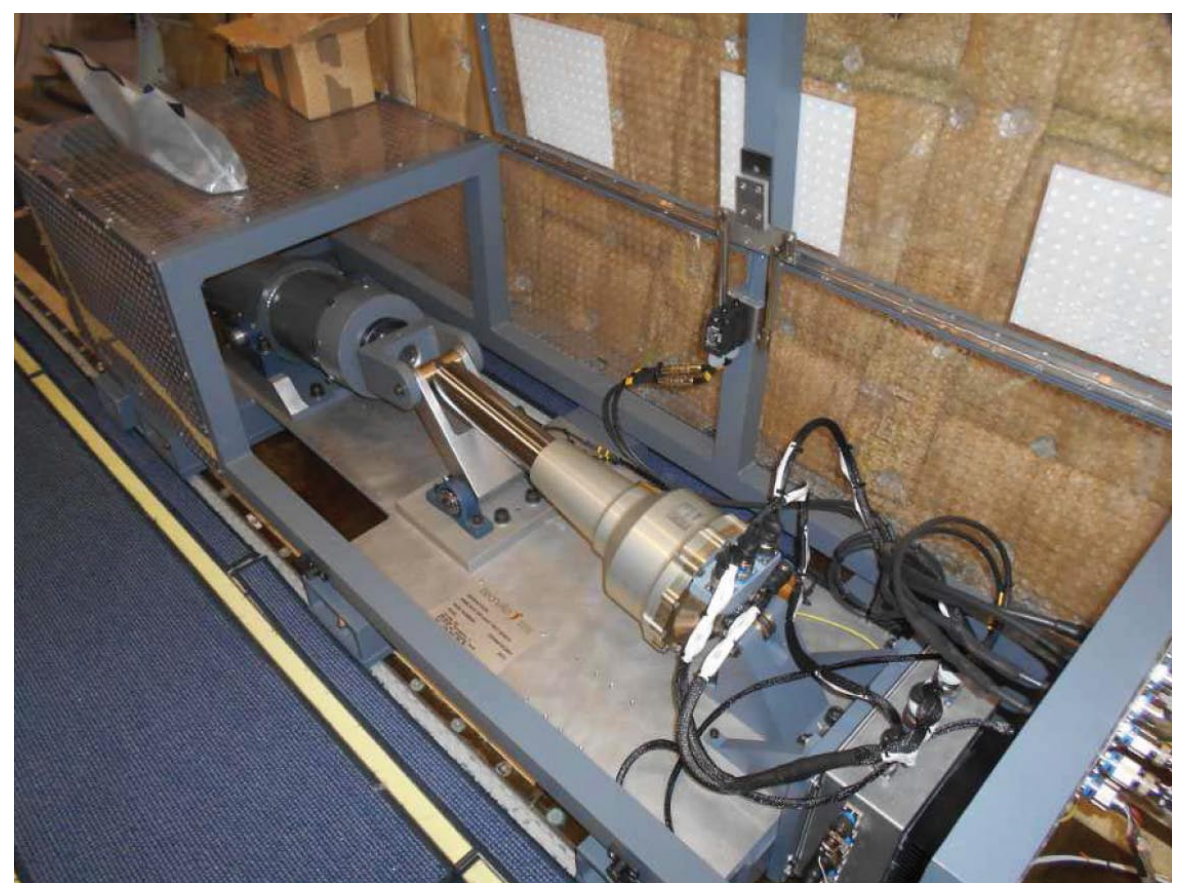

4. irudia. Lurreratze-trena eragiteko EMAren entsegu-plataforma, ATR hegazkin komertzial baten karga-kabinan muntatuta.

Aktuadore-kopurua eta mota asko aldatzen da hegazkin-motaren arabera. Horrez gainera, ezberdintasun nabarmenak daude aktuadore ezberdinen artean. Adibidez, slatek jasan beharreko karga oso txikia da (kW gutxi batzuetakoa); aldiz, timoiak eta jasotzaileek $50 \mathrm{~kW}$ eta $60 \mathrm{~kW}$ bitarteko kargak jasan behar dituzte $[1,6,8]$. Beraz, diseinatu beharreko potentziasistemak eta motorrak ezberdinak izango dira.

Kargen profil dinamikoan ere ezberdintasun nabarmenak aurkitu daitezke. Adibidez, lurreratze-trenak luzapen-eremu zabala bete behar du, baina lur hartzean edo aireratzean eragin behar da bakarrik. Bestalde, hegaldiko kontrol primariorako azalerak aldioro erabiltzen dira hegaldian zehar, baina mugimendu laburrak gauzatu behar dituzte, zuzenketa leunak egiteko [9].

Kontuan izan beharreko beste faktore bat da aktuadore batzuek muturreko baldintzetan egin behar dutela lan hegaldiko egoera zehatz batzuetan. Adibidez, hegal bateko propultsio-motor guztiek huts egiten badute, timoia posizio finkoan mantendu behar da, angelu nabarmen batekin. Egoera horretan normalean baino momentu gehiago sortu beharko du aktuado- 
reak [10]. Azkenik, kontuan izan behar da klimatikoki muturreko egoeretan funtzionatzen dutela aktuadoreek, hori da, $-60{ }^{\circ} \mathrm{C}$ eta $+70{ }^{\circ} \mathrm{C}$ bitarteko tenperatura-inguruneetan egiten dute lan; hegazkinak altuera lortzen duenean, 0 eta 1 bar arteko presioekin [6]. Beraz, argi dago sistemaren diseinua kritikoa dela aktuadoreetan.

Lan honen sarreran aipatu bezala, aktuadore hidrauliko konbentzionalak aktuadore elektromekanikoengatik (EMA, Electro Mechanical Actuator, ingelesez) ordezkatzea planteatzen da MEA kontzeptuan. Potentzia-elektronika beharko da horretarako. Torloju bati eragingo dio motor elektrikoak kaxa erreduktore baten bitartez, 5(a). irudian erakusten den bezala. Atal hidraulikoak kentzen direnez, EMAk fidagarriagoak eta eraginkorragoak dira [2,3]. Hala ere, EMA horiek parte mekanikoetan trabaketak izan ditzakete (kaxa erreduktorean edo torlojuan); ondorioz, beharrezkoa da azken hori diseinuan kontuan izatea [1,6].

Azken eragozpen hori saihestu ahal izateko, aktuadore elektro-hidrostatikoak (EHA, Electro Hydrostatic Actuator ingelesez) proposatu dira azken urteotan. Zirkuitu hidrauliko itxi bat duen unitate bat da EHA, motor elektriko batek eragindako ponpa hidrauliko baten bidez olioaren mugimendua eta zilindro hidraulikoaren konpartimenduen arteko presio-ezberdintasunak kontrolatzen dituena. EHA baten funtzionamendu-printzipioa erakusten du 5(b). irudiak [3]. Zilindroaren eta motorraren artean konexio mekaniko zuzenik ez dagoenez, oso arraroa litzateke horrelako sistema bateko atal mekanikoetan trabaketak gertatzea.

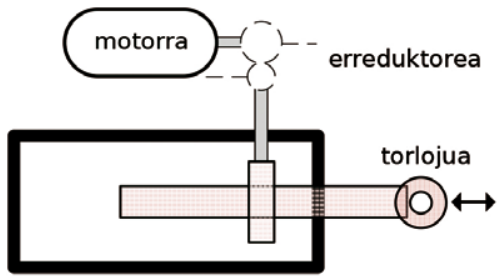

(a)

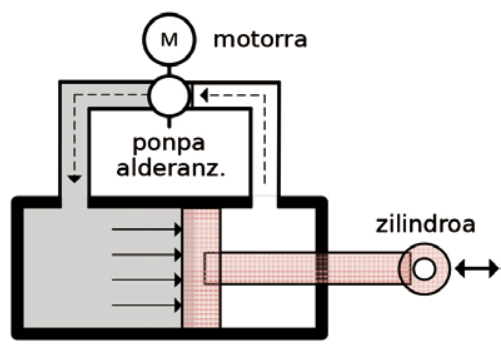

(b)

5. irudia. (a) EMA eta (b) EHA motako aktuadoreak.

Atal honekin amaitzeko, EMA baten funtzionamendu erreala ilustratuko da. Alde horretatik, egileek Tecnalia Research and Innovationek Donostian duen saiakuntza-laborategian instalatutako EMAn (6. irudia) [11] lortutako emaitzen adibideak azalduko dira. EMA horren helburua da eskualdeko hegazkin baten timoiaren posizioan eragitea, lan baldintzen arabera eta haizeak sortutako kargari aurre eginez, erreferentziazko posizio 
bati jarraituz. Horretarako, iman iraunkorreko makina sinkrono (PMSM, Permanent Magnet Synchronous Machine) baten momentu elektromagnetikoa (7(a). irudia) eta abiadura (7(b). irudia) kontrolatzen dira, horrek EMAren torlojuari era egokian eragiteko. Ondorioz, timoiak desiratutako posizio-erreferentzia jarraitzen du (7(c). irudia). Alde horretatik, posiziokontrolagailuak sortzen du erreferentziazko abiadura, erreferentziazko posizioaren eta timoiaren posizio errealaren arteko errorea ezeztatuz. Behin erreferentziazko abiadura zehaztuta eta makinaren abiadura ezagututa, PI (Proportional Integral) erreguladore baten bidez momentu elektromagnetikoari dagokion erreferentzia sortzen du abiadura-kontrolak. Azkenik, FOC (Field Oriented Control, ingelesez) kontrol-egitura erabili da PMSMaren momentu elektromagnetikoaren kontrolerako [12].

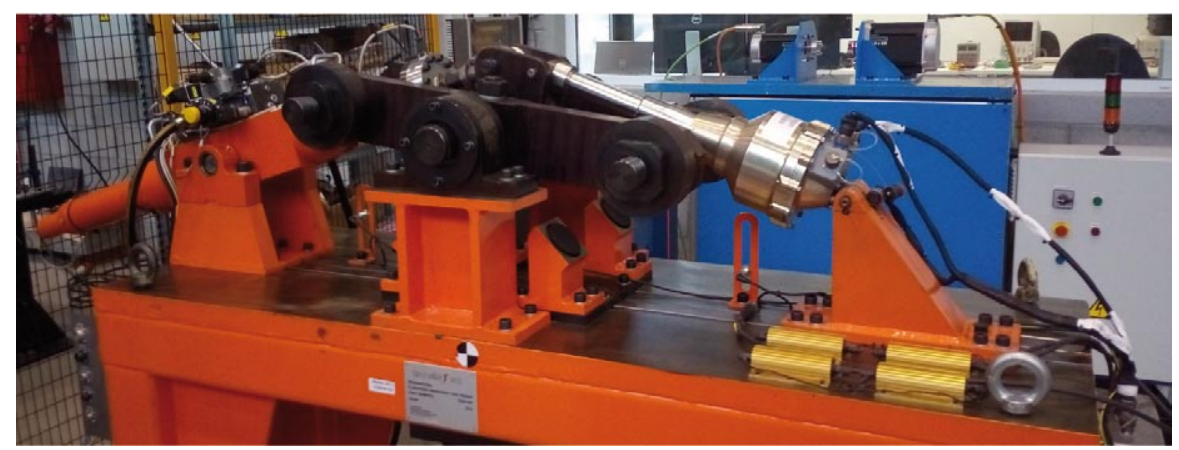

6. irudia. Timoiari eragiteko EMA eta hegazkinaren funtzionamendu errealari dagokion karga emulatzen duen entsegu-bankua, Donostiako Tecnalia Research and Innovationen saiakuntza-laborategian.

PMSMak oso egokiak dira aplikazio aeronautikoetarako, mota horretako aplikazioetan desiragarriak diren ezaugarriak baitituzte, hala nola eraginkortasun altua, fidagarritasuna eta potentzia-dentsitate handiak, besteak beste [13]. Fidagarritasuna ezinbestekoa da hegazkinetan, bidaiarien segurtasuna baitago jokoan. Bestalde, potentzia-dentsitatea ere kritikoa da, sistemen pisua murrizteak erregaien kontsumoa murrizten baitu. Tecnalian garatutako EMA horrek hiru fasedun motor-teknologia darabil, gaur egungo aplikazio industrialetan konfigurazio ohikoena eta zabalduena dena. Hala ere, 4. atalean azalduko den bezala, fase anitzeko konfigurazioak kontsideratzen ari dira komunitate zientifikoan, hurrengo belaunaldiko sistemak gauzatzeko, kritikoak diren segurtasuna eta potentzia-dentsitatea oraindik ere gehiago hobetu ditzaketelako. 


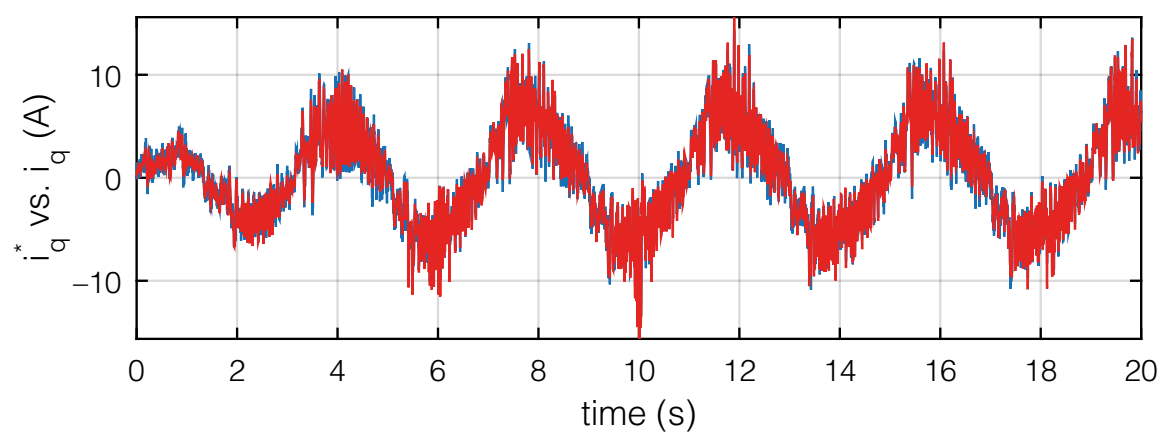

a) Estatoreko korrontearen kontrola, aldiune bakoitzean beharrezkoa den momentu elektromagnetikoa sortzeko.

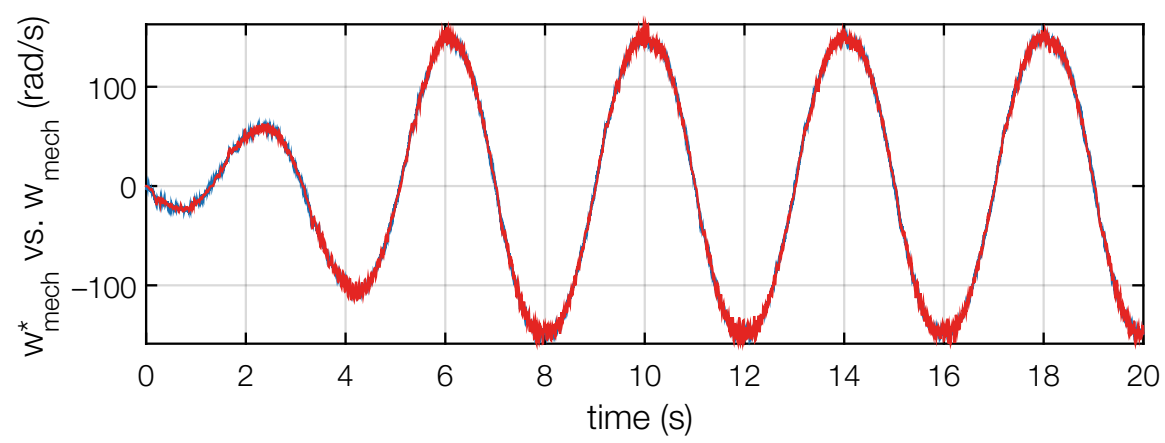

b) Abiadura-kontrolaren emaitzak.

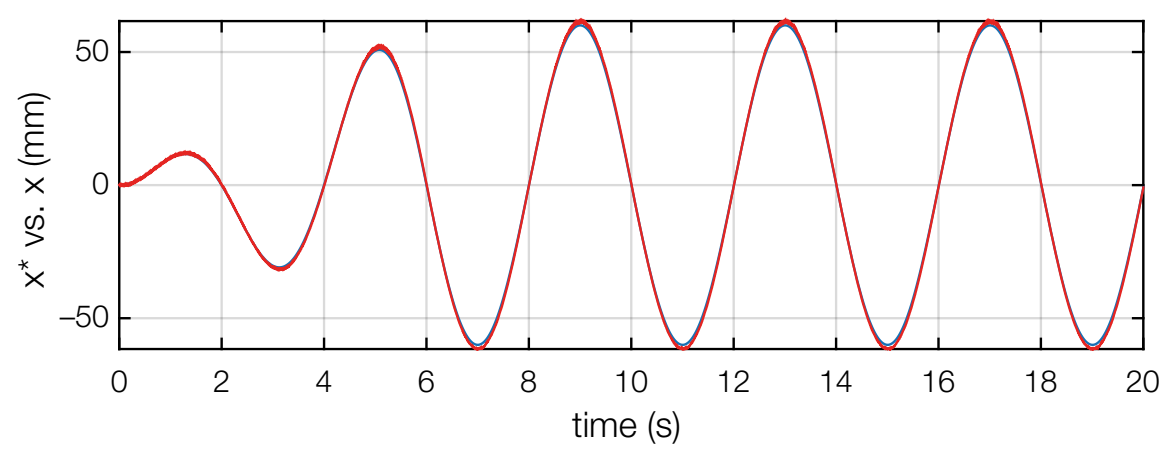

c) Posizio-kontrolaren emaitzak.

7. irudia. EMA errealean lortutako emaitza esperimentalen adibideak lan-baldintza zehatz baterako. 


\section{PROPULTSIO ELEKTRIKOA ETA HIBRIDOA HEGAZKINETAN}

Nahiz eta sistema pneumatikoen, hidraulikoen eta mekanikoen ordezkapenak erregai fosilen aurrerapen nabarmena ekarri, hori ez da nahikoa zenbait erakunde kontsideratzen ari diren aurrezpen-helburuak lortzeko. Adibidez, Advisory Council for Aviation Research and innovation in Europe (ACARE) elkartearen helburua da \% 80ko murrizketak lortzea nitrogeno oxidoen $(\mathrm{NO} x)$ isurketetan, eta \% 20ko murrizketak lortzea $\mathrm{CO}_{2}$ isurketetan [14, 15]. Bestalde, Europar Batasuneko «Flightpath 2050» txostenean 2050erako \% 75eko murrizketa proposatzen da helburutzat, $\mathrm{CO}_{2}$ isurketei dagokienez, 2000. urteko isurketa-tasekin konparatuz. Horrez gain, \% 90eko NOx kutsatzaileen murrizketa proposatzen da, bai eta $\%$ 65eko murrizketa hegazkinek sortzen duten zaratan ere. Horrenbestez, komunitate zientifikoan adostasuna dago onartzean ezinbestekoa dela hegazkinen propultsio-sistemen elektrifikazio partziala edo totala (8. irudia).

Ibilbide ertaineko (eskualde-hegaldiak) edo luzeko hegazkinen elektrifikazioaz aparte, aztergai dago hiriguneetako airezko garraioaren bideragarritasuna. Mugikortasunerako modalitate horrek aurrerapen ekonomiko, ekologiko eta sozial interesgarriak sor ditzake, biztanle-dentsitate handia daukaten tokietan aerotaxiak erabiliz, garraio azkar, ekologiko eta zarata baxukoa ahalbidetuz.

Hala ere, hegazkinen propultsio-sistemaren elektrifikazio osoa gauzagarria izan dadin, beharrezkoa da egun energia elektrikoa metatzeko erabiltzen diren sistemek inposatzen dituzten mugak gainditzea. Alde batetik, energia espezifikoa handitu behar da nabarmen. Alde horretatik $[16,17,18]$, erreferentzien arabera, hegazkinen elektrifikazio osoa gauzatzeko beharrezkoa da, gutxienez, $500 \mathrm{Wh} / \mathrm{kg}$-ko energia espezifikoa lortzea eskualde-hegaldietan edota distantzia luzeko hegaldietan. Hala ere, gaur egungo baterien teknologiak $250-300 \mathrm{Wh} / \mathrm{kg}$ bitarteko energia espezifikoa eskaintzen du. Oso energia espezifiko baxua da, batez ere hegazkinaren kerosenoarekin konparatuz $(12 \mathrm{kWh} / \mathrm{kg})$. Hala ere, literatura zientifikoan aurreikusten da 2030 urterako energia elektrikoa metatzeko sistemek $650 \mathrm{Wh} / \mathrm{kg}$-ko muga gaindituko dutela $[16,17,18]$.

Hegazkinen propultsioaren elektrifikazio osoaren erdibideko alternatiba da motor elektrikoak eta konbustiozko motorrak konbinatzea, sorgailu elektrikoekin, metaketa-sistemekin eta erregai-gelaxkekin batera. Hibridazio horrek hainbat konfigurazio posible izan ditzake, 8. irudiak erakusten duen bezala. Hau da, 8(a). irudiko goialdean erregai fosiletan oinarritutako propultsio-sistema aurkezten da. Aldiz, beheko aldean guztiz elektrikoa den propultsio-sistema erakusten da, baterien bidez elikatuta dagoena. Erdian zenbait konfigurazio hibrido azaltzen dira, konbustio-motorrak eta sistema elektrikoak konbinatzen dituztenak. 


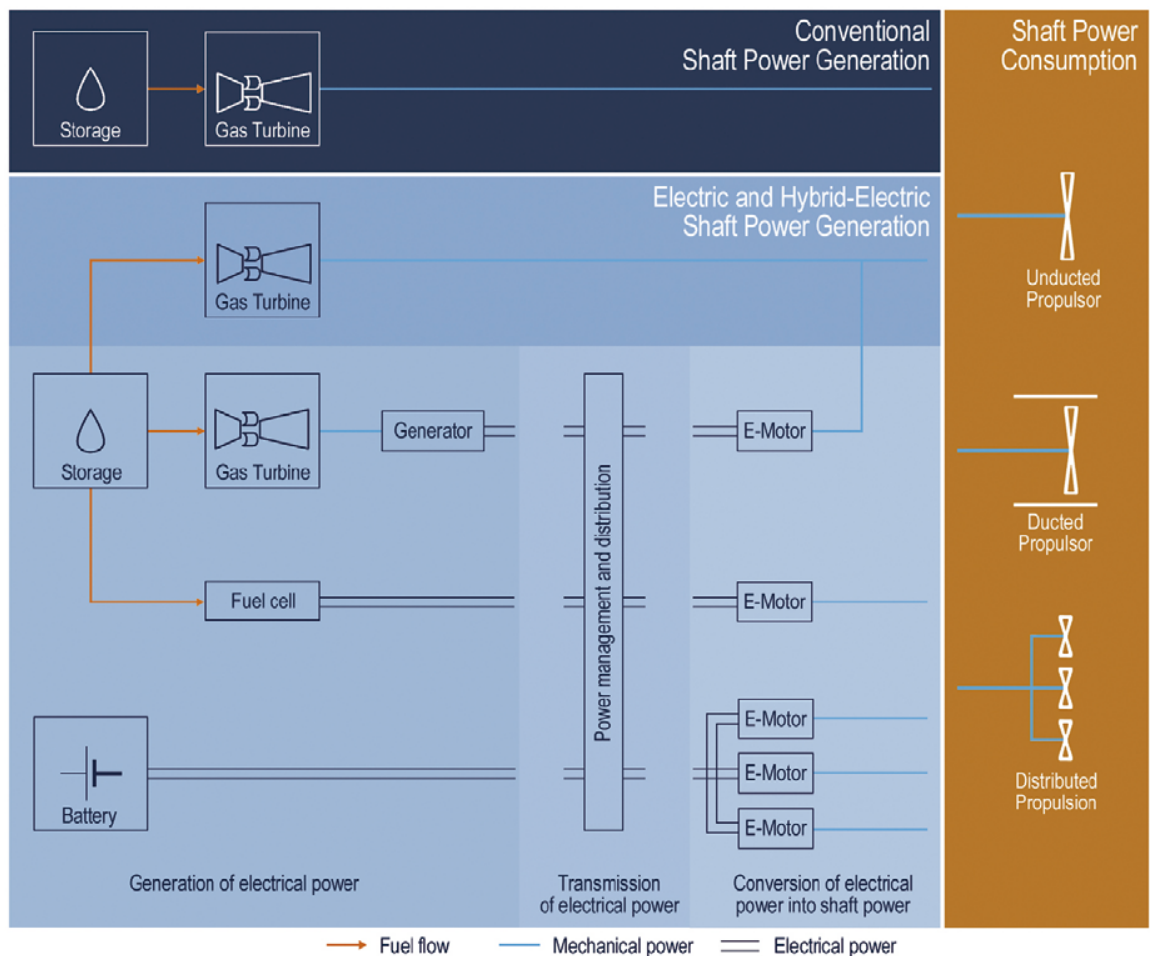

a.

\section{Serial Hybrid Solutions}
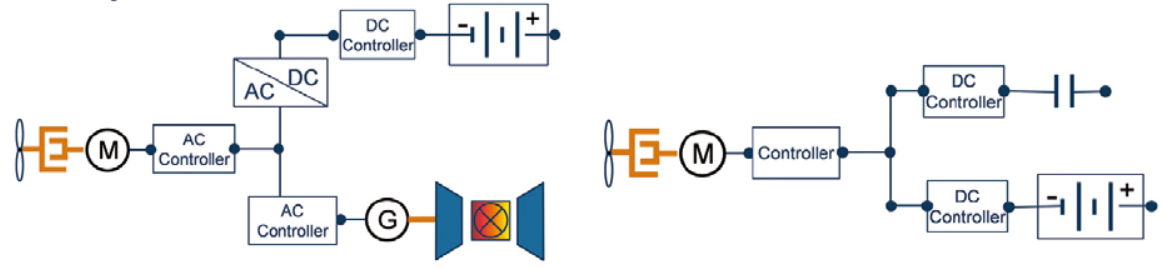

Parallel Hybrid Solutions
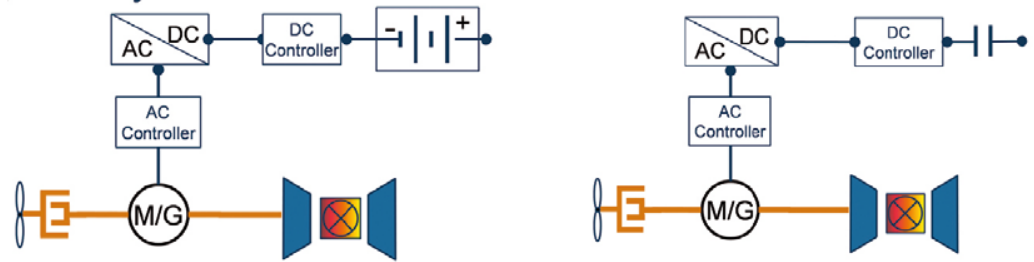

b.

8. irudia. Hegazkinen propultsio elektriko eta hibridorako arkitekturak [15]. 
Bi motatakoak izan daitezke konfigurazio hibrido horiek, hau da, serie edo paralelo konfigurazioak, 8(b). irudian erakusten den bezala. Serie konfigurazioan motor elektrikoa bakarrik arduratzen da helizeen mugimenduaz. Hala ere, energia-iturri ezberdinen konbinazioari esker elikatzen da motor elektriko hori. Horien artean konbustiozko motorrak, sorgailu elektrikoak, superkondentsadoreak, bateriak edota erregai-pilak konbinatzen dituztenak daude. Aldiz, helizeak biratzen dituzte motor elektrikoak eta erregai fosildun motorrak. Bai serie eta ba paralelo konfigurazioetan, konbustiozko motorra eta sorgailu elektrikoa konbina daitezke bateriak berriz kargatzeko.

Beraz, aurrekotik argi geratzen da propultsio elektrikoak edota hibridoak motor elektriko eraginkorrak behar dituela, potentzia-dentsitate handiarekin (pisua eta bolumena ahalik eta gehien murrizteko), eta nolabaiteko hutsegite-tolerantzia mailarekin (segurtasuna dela eta). Horrela, motor konpaktu eta txikiak garatuz gero, propultsio banatua duten arkitekturak garatu daitezke, hainbat motor elektriko konbinatuz hegazkinaren propultsioa gauzatzeko [16]. Horrela, hegazkinaren diseinua malgua izan daiteke, eta aerodinamika hobetzen duten diseinuak aukeratu daitezke [19]. Ezaugarri horiek lortzeko eta artearen egoera kontuan izanda, iman iraunkorreko fase anitzeko (hiru fase baino gehiagoko) motor elektrikoak nabarmendu daitezke aukera bideragarrientzat [2, 20, 21, 22, 23].

\section{ETORKIZUNERAKO FASE ANITZEKO POTENTZIA-SISTEMAK HEGAZKINETAN}

Oro har, hiru faseko motor elektrikoak erabiltzen dira aplikazio industrial gehienetan. Adibidez, mota horretako sistemak dira 4. eta 6. irudietan azaldutako EMA sistemak. Hiru fase erabiltzearen arrazoia historikoa da, zeren eta motor elektrikoak energia elektrikoa banatzeko sare trifasikoarekin elikatu izan baitira zuzenean. Hala ere, potentzia-elektronikaren garapenari esker (motorra AC edo DC iturri batetik elikatu dezakeen teknologia), ez dago, teorikoki, mugarik horrelako sistema baten fase-kopuruari dagokionez (konplexutasuna handitzeak sortzen duen mugaz aparte) [24]. Alde horretatik, fase anitzeko sistemek hurrengo abantailak eskaintzen dituzte $[20,25]$ :

- Momentu elektromagnetikoaren uhinduraren murrizketa. Makina elektrikoak sortzen duen momentu elektromagnetikoa estatoreko korronteekin erlazionatuta dago. Fase anitzeko makinetan korronte horien kalitatea hobetzen denez, hobea izango da makinak sortuko duen momentu elektromagnetikoaren uhindura.

- DC-linkeko osagai harmonikoen murrizketa. Bihurgailuaren sarrerako kondentsadorean sortutako korronteen uhindura murrizten 
da. Ondorioz, kondentsadorearen potentzia-galerak murrizten dira, elementu kritiko horren bizi-zikloa luzatuz, edota dimentsionamendua erraztuz.

- Faseko zirkulatzen duen potentziaren eta korrontearen murrizketa. Potentzia eta tentsio jakin baterako, fase bakoitzetik zirkulatu behar duen korrontea murriztu egiten da, faseak gehitu ahala. Era horretara, posible da korrontea eramateko gaitasun gutxiago daukaten gailu erdieroaleak erabiltzea.

- Eraginkortasunean hobekuntza. Fase bakoitzetik zirkulatzen duen korrontea murrizten denez, potentzia-galerak murriztu egin daitezke, gailu erdieroaleak era egokian dimentsionatuz gero.

- Fidagarritasun handia, hutsegite-tolerantziari esker. Motor elektrikoan kontrolagarriak diren askatasun-graduak handitu egiten dira, fase-kopurua handitzean. Adibidez, hiru fase dituzten motor konbentzionaletan (kargan izar konexioa dutenak) bi askatasun-gradu daude, motorraren fluxua eta momentu elektromagnetikoa kontrolatzeko erabiltzen direnak. Hiru fase dituen sistema bateko fase batean hutsegitea gertatuz gero, ezin daiteke kontrol hori gauzatu eta motorrak ezin du funtzionatzen jarraitu. Aldiz, posible da sistema funtzionamendu pseudo-optimoan mantentzea, fase-kopurua handitu ezkero, sistemak bere eginkizuna betez.

Alde horretatik, eta salbuespenak salbuespen, aplikazio aeronautikoetarako erabilgarriak izan daitezkeen fase anitzeko hiru topologia nagusi desberdindu daitezke (9. irudia). Kasu askotan elikadura-iturria DC motakoa denez, bi mailatako inbertsoreak erabiltzen dira, potentzia-bihurgailutzat (hala ere, beste aukera posible batzuk ere kontsidera daitezke sare elektrikoaren naturaren arabera, edo desiragarriak izan daitezkeen beste ezaugarri batzuen arabera, hala nola potentzia-bihurgailu matrizialak [26] edota maila anitzeko bihurgailuak [27]).

Fase anitzeko konfigurazio konbentzionala erakusten du 9(a). irudiak, makinaren harilkatuak izar konexioa duena. Konfigurazio horrek $n$ fase izan ditzake (normalean fase-kopurua bakoitia da, modulazioa eta kontrola sinplifikatuz), eta simetrikoki banatuta daude fase horiek, hau da, ondoz ondo dauden bi faseren arteko angelua $2 \pi / \mathrm{n}$-koa da. Alde horretatik, $n-1$ askatasun gradu ditu topologia horrek, hainbat harmonikoren aldibereko kontrola posible eginez (10. irudia). Era horretara eta makinaren harilkatuaren bidez kontrolagarriak diren harmonikoei dagozkien indar elektroeragilearen osagaiak sortuz, posible da, gutxi gorabehera, momentu elektromagnetikoa sortzeko gaitasuna \% 15ean handitzea [28]. Horrez gain, hutsegiteak gertatzen direnean motorrak operazio pseudo-optimoan lan egiten jarraitzeko erabil daitezke harmoniko horiek [21]. Horrelako motorrak aeronautikan erabiltzen dituzten hainbat erreferentzia aurkitu daitezke literatura zientifikoan $[29,30,31]$. 
Bigarren topologia nagusia hiru faseko egitura aniztzat bezala ezagutzen da, eta haien artean isolatuta dituzten $m$ harilkatu trifasikoz osatzen da. Alde horretatik, hiru faseko $(n=3 m)$ konfigurazio duala erakusten du 9(b). irudiak. Faseak uniformeki daude espazioan banatuta multzo bakoitzean, hau da, bi faseren arteko angelua $2 \pi / 3 \mathrm{da}$, makina konbentzionaletan bezala. Harilkatu-talde bakoitzaren artean $2 \alpha$ desplazamendu-angelua definitzen da; beraz, faseak ez daude simetrikoki banatuta espazioan (11. irudia). Momentu elektromagnetikoan sortutako pultsazioei eragiten die, batez ere, desplazamendu-angeluak. Alde horretatik, $2 \alpha=\pi / 6$ rad kontsidera daiteke aukera egokiena [32].

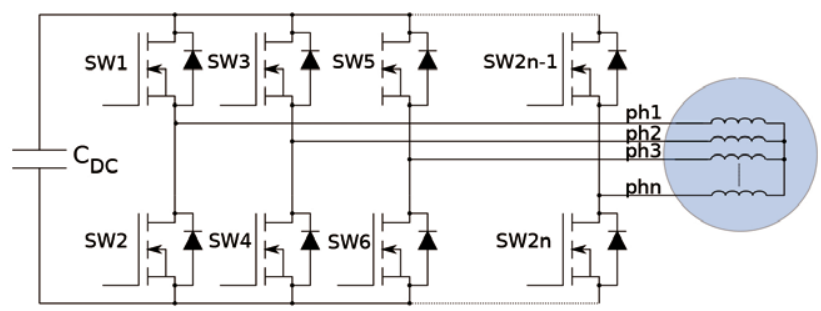

(a) Fase anitzeko konfigurazio konbentzionala, makinaren harilkatua izar konexioa duena.

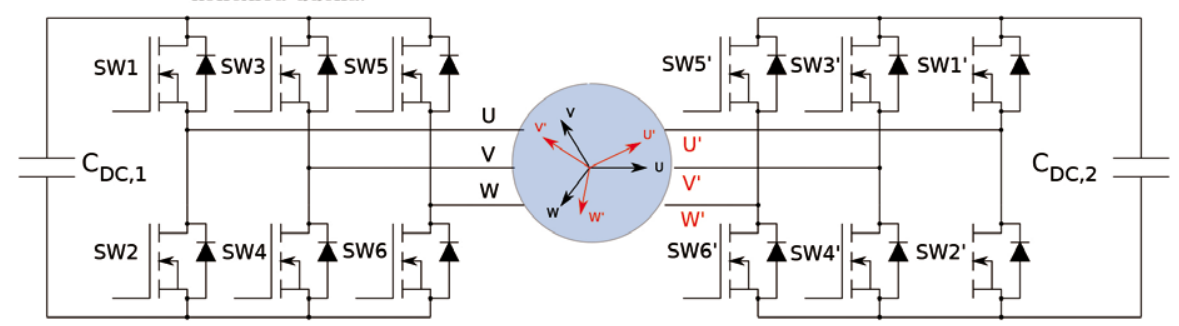

(b) Hiru faseko konfigurazio duala, guztira sei fase dituena.

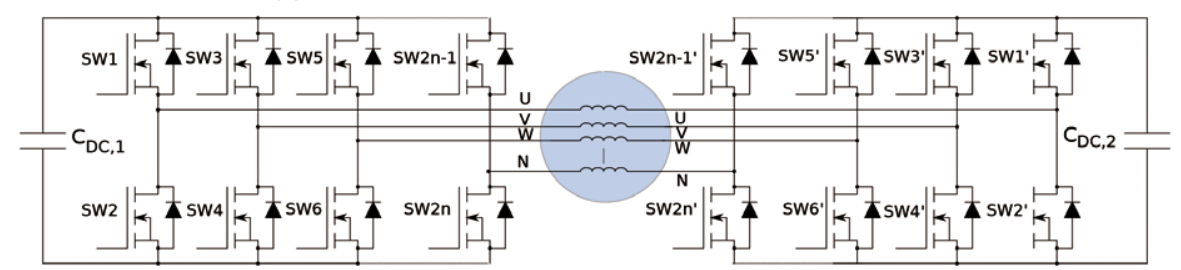

(c) Harilkatu irekiko fase anitzeko konfigurazioa.

9. irudia. Fase anitzeko potentzia-sistemen konfigurazio ohikoenak. 


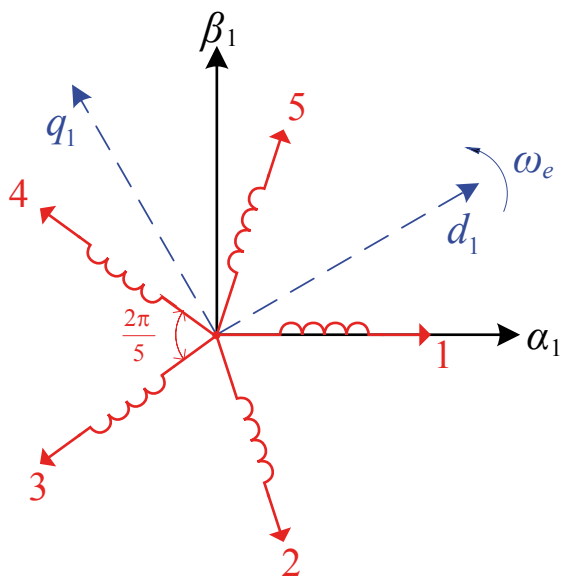

a)

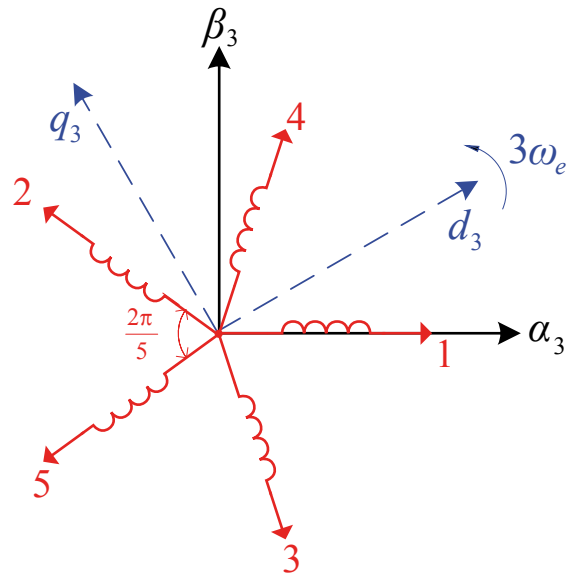

b)

10. irudia. 5 fase dituen eta harilkatua izarrean duen motorraren harilkatuak (gorriz) eta kontrolagarriak diren askatasun-graduak (urdinez). (a) irudia harmoniko fundamentalari dagokio eta (b) irudia hirugarren harmonikoari.

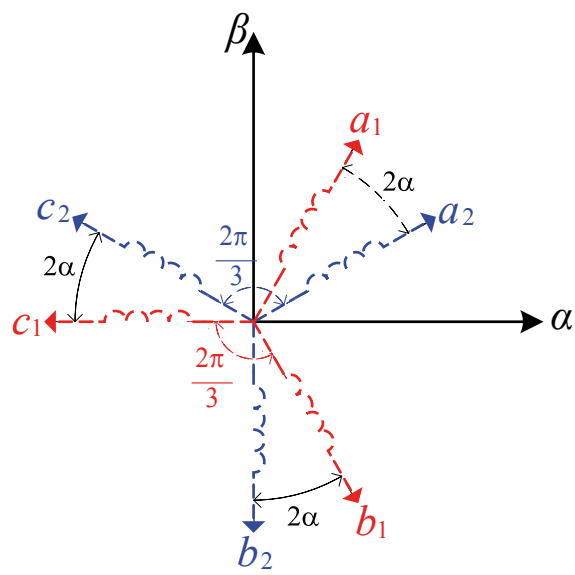

11. irudia. Hiru fase dituen harilkatu dualeko motorraren konfigurazio espaziala, $2 \alpha$ desplazamendu-angeluaren menpe.

Aukera teknologiko horren abantaila nagusiak dira kontrola sinplea dela eta sistema trifasikoetarako erabiltzen den teknologia berrerabil daitekeela [13]. Gainera, multzo trifasiko bakoitzak bere elikadura independentea izan dezake; beraz, iturriaren hutsegiteekiko tolerantzia hobetzen 
da [13]. Hala ere, kontuan izan behar da kasu honetan askatasun-graduen kopurua txikiagoa dela (bi askatasun gradu talde trifasiko bakoitzeko). Talde trifasiko batean hutsegitea gertatzen bada, deskonektatu egin behar da eta beste taldeek jasan beharko dute huts egin duen taldearen potentzia. Beraz, sistema gaindimentsionatu egin behar da $100 \%$-eko operazioa bermatzeko, hutsegitea gertatu ondoren. Aukera hori darabilten hainbat adibide aurkitu daitezke literatura zientifikoan $[33,34]$.

Azkenik, harilkatu irekiko topologia izenez ezagutzen da hirugarren topologia (9(c). irudia). Fase bakoitzak bihurgailu monofasiko independente bat dauka, hutsegite-tolerantzia oso handia eskainiz [24]. Horrez gainera, DC-linkaren aprobetxamendu onena lortzen da konfigurazio horretan. Ordainetan, muntatu behar den potentzia-elektronikaren konplexutasuna handiena da, beste aukerekin konparatuz gero.

\section{ONDORIOAK}

Artearen egoeraren azterketatik ondoriozta daiteke MEA kontzeptuak aukera handiak sortuko dituela hurrengo urteotan, bai mundu akademikoan, eta bai alor industrialean ere. Garatu beharreko teknologia hasierako etapetan dago oraindik, eta garapen teknologiko oso handia aurreikusten da. Azaldutako adibide praktikoetan ikus daitekeenez, MEA sistemen funtzionamendu egokia lor daiteke gaur egun dagoen teknologiarekin (hiru faseko sistemak barne). Hala ere, fase anitzeko potentzia-sistemek aukera berriak sortuko dituzte etorkizuneko sistemetan, horien ezaugarriak (eraginkortasuna, fidagarritasuna, dimentsionamendua eta hutsegite-tolerantzia, besteak beste) hobetuz, eta hegazkinetan sistema elektrikoen ezarpena erraztuz.

\section{ESKERRAK}

Argitalpen honetan aurkeztutako lana Eusko Jaurlaritzaren Kultura eta Hizkuntza Politika Sailak babestu du, euskal unibertsitate-sisteman diren ikerkuntza-taldeen (IT978-16) jarduera babesten duten laguntzen barne. Horrez gain, Ministerio de Economía y Competitividad ek babestu du (DPI2014-53685-C2-2-R proiektua eta FEDER funtsak), bai ere Eusko Jaurlaritzak, ELKARTEK programako KT4TRANS proiektuaren barruan (KK-2015/00047 y KK-2016/00061) eta Europar Batasunak FP7-JTI (JTICS-2012-GRA-03-009, 323318. erreferentzia) eta FP7-JTI (JTI-CS-2011GRA-03-005, 298176. erreferentzia) proiektuen baitan. 


\section{BIBLIOGRAFIA}

[1] WHEELER, P.W., ClARE, J. TRENTIN, A., BOZHKO, S. 2012. «An overview of the more electric aircraft», Journal of Aerospace Engineering, 227, 578-585.

[2] CAO, W., MECROW, B.C., ATKINSON, G.J., BENNET, J.W., ATKINSON, D.J. 2012. «Overview of Electric Motor Technologies Used for More Electric Aircraft (MEA)», IEEE Transactions on Industrial Electronics, 59(9), 3523-3531.

[3] MAZZOLENI, M., MACCARANA, Y., PREVIDI, F., PISPOLA, G., NARDI, M., PERNI, F., TORO, S. 2017. «Development of a reliable electro-mechanical actuator for primary control surfaces in small aircrafts)», IEEE International Conference on Advanced Intelligent Mechatronics (AIM)-eko aktetan.

[4] BENNETT, J.W. 2010. «Fault Tolerant Electromechanical Actuators for Aircraft», Doktorego Tesia, Newcastle-eko Unibertsitatea.

[5] BENNETT, J.W., MECROW, B.C., ATKINSON, D.J., ATKINSON, G.J. 2011. «Safety-critical design of electromechanical actuation systems in commercial aircraft», IET Electric Power Applications, 5(1), 37-47.

[6] BOGlietTI, A., CAVAGNinO, A., TENCONI, A., VASCHETTO, S. 2009. «The safety critical electric machines and drives in the more electric aircraft: A survey», Annual Conference of IEEE Industrial Electronics-eko aktetan.

[7] «Final Report Summary-ARMLIGHT (Design, development and manufacturing of an electro-mechanical actuator and test rig for AiRcrafts Main LandIng Gear acTuation systems)», CORDIS, sarean eskuragarri: https:// cordis.europa.eu/result/rcn/192742_en.html

[8] ROBSON, P.A., BRADley, K.J., WHEEler, P., ClARE, J., DE LILLO, L., GERADA, C., PICKERING, S.J., LAMPARD, D., GOH, C.K., TOWERS, G., WHITLEY, C. 2003. «The impact of matrix converter technology on motor design for an integrated flight control surface actuation system», IEEE International Electric Machines and Drives Conference-ko aktetan.

[9] TRAINER, D.R. 2002. «Electric actuation - power quality management of aerospace flight control systems», International Conference on Power Electronics Machines and Drives-eko aktetan.

[10] GARCIA, A., CUSIDO, J., ROSERO, J.A., ORTEGA, J.A., ROMERAL, L. 2008. «Reliable electro-mechanical actuators in aircrafts», IEEE Aerospace and Electronic Systems Magazine, 23(8), 19-25.

[11] «Final Report Summary - FLIGHT-EMA (E-RUDDER) (Advanced Flight control system Design Development and Manufacturing of an Electro Mechanical Actuator with associated Electronic Control Unit and Dedicated test Bench)», CORDIS, sarean eskuragarri: https://cordis.europa.eu/result/ rcn/192740_es.html 
[12] TRANCHO, E., IBARRA, E., ARIAS, A., SABIHI, N., LÓPEZ, I. 2017. «Ibilgailu elektrikoen propultsio-sistemak: motor elektrikoak eta horien kontrola», Ekaia, Potentzia-elektronika: teknologia eta aplikazioak (ale berezia), 61-82.

[13] BOJOI, R., CAVAGNINO, A., TENCONI, A., TESSAROLO, A., VASCHETTO, S. 2015. «Multiphase electrical machines and drives in the transportation electrification», 2015 IEEE 1st International Forum on Research and Technologies for Society and Industry Leveraging a better tomorrow (RTSI)-eko aktetan.

[14] HENKE, R., DE GROOT, R., MACHENHEIM, M. 2017. «Strategic Research \& Innovation Agenda», Advisory Council for Aviation Research and Innovarion in Europe.

[15] PORNET, C., ISIKVEREN, A.T. 2015. «Conceptual design of hybrid-electric transport aircraft», Progress in Aerospace Sciences, 79, 114-135.

[16] THOMSON, R., SACHDEVA, N., MAXIM, N. AND MARTINEZ, N. 2017. «Aircraft Electrical Propulsion The Next Chapter Of Aviation? It Is Not A Question Of If, But When», Roland Berger GmbH.

[17] HOELZEN, J., LIU, Y., BENSMANN, B., WINNEFELD, C., ELHMAN, A., FRIEDRICHS, J., HANKE-RAUSCHENBACH, R. 2018. «Conceptual Design of Operation Strategies for Hybrid Electric Aircraft», Energies, 11(1), 1-26.

[18] STUECKL, S. 2015. «Methods for the Design and Evaluation of Future Aircraft Concepts Utilizing Electric Propulsion Systems», Doktorego Tesia, Technische Universitat Munchen.

[19] GOHARDANI, A.S., DOULGERIS, G., SINGH, R. 2011. «Challenges of future aircraft propulsion: A review of distributed propulsion technology and its potential application for the all electric commercial aircraft», Progress in Aerospace Sciences, 47(5), 369-391.

[20] BARRERO, F., DURAN, M.J. 2016. «Recent Advances in the Design, Modeling, and Control of Multiphase Machines-Part I», IEEE Transactions on Industrial Electronics, 63(1), 449-458.

[21] DURAN, M.J., BARRERO, F. 2016. «Recent Advances in the Design, Modeling, and Control of Multiphase Machines - Part II», IEEE Transactions on Industrial Electronics, 63(1), 459-468.

[22] KUANG, Z., ZHAO, T., CUI, S. 2016. «Five-phase permanent magnet synchronous motor drive for aircraft applications», UKACC International Conference on Controleko aktetan.

[23] ZJAMG. X., JARAM. S. 2016. «High-specific-power electric machines for electrified transportation applications-technology options», IEEE Energy Conversion Congress and Exposition (ECCE)-ko aktetan.

[24] BOJOI, R., RUBINO, S. TENCONI, A., VASCHETTO, S. 2016. «Multiphase electrical machines and drives: A viable solution for energy generation and transportation electrification», International Conference and Exposition on Electrical and Power Engineering (EPE)-eko aktetan. 
[25] KARTTUNEN, J., KALLIO, S., PELTONIEMI, P., SILVENTOINEN, P., PRYHONEN, O. 2014. «Decoupled Vector Control Scheme for Dual ThreePhase Permanent Magnet Synchronous Machines», IEEE Transactions on Industrial Electronics , 61(5), 2185-2196.

[26] IBARRA, E., ANDREU, J., KORTABARRIA, I., MARTÍNEZ DE ALEGRÍA, I., MARTIN, J.L., ETXEBARRIA, J.R. 2010. «Potentzia-bihurgailu matriziala: teknologia eraginkor eta konpaktua», Ekaia, 23, 173-197.

[27] NABAE, A., TAKAHASHI, I., AKAGI, H., 1981. «A New Neutral-PointClamped PWM Inverter», IEEE Transactions on Industry Applications, IA17(5), 518-523.

[28] PARSA, L., TOLIYAT, H. 2005. «Five-phase permanent-magnet motor drives», IEEE Transactions on Industry Applications, 4(1), 30-37.

[29] GERADA, C., BRADLEY, K., HUANG, X., GOODMAN, C., WHITLEY, C., TOWERS, G. 2007. «A 5-phase fault-tolerant brushless permanent magnet motor drive for an aircraft thin wing surface actuator», IEEE International Electric Machines \& Drives Conference-ko aktetan.

[30] HUANG, X., GOODMAN, A., GERADA, C., FANG, Y., LU, Q. 2012. «Design of a five-phase brushless DC motor for a safety critical aerospace application», IEEE Transactions on Industrial Electronics, 59(9), 35323541.

[31] NOIA, L., RIZZO, R. 2017. «Design of a five-phase permanent-magnet motor for the electric steering of an aircraft nose landing gear», IET Electrical Systems in Transportation, 7(4), 327-333.

[32] KALLIO, S. 2014. «Modeling and parameter estimation of double-star permanent magnet synchronous machines», Doktorego Tesia, Lappeenranta University of Technology.

[33] ALNAJJAR, M., GERLING, D. 2016. «Six-phase electrically excited synchronous generator for more electric aircraft», International Symposium on Power Electronics, Electrical Drives, Automation and Motion (SPEEDAM)eko aktetan.

[34] DAI, W., XIU, T., HANG, H., YAN, Y. 2006. «Control of a novel dual stator doubly salient aircraft engine starter-generator», IEEE Power Electronics Specialists Conference (PESC)-eko aktetan. 